\title{
Very clever homunculus: Compound stimulus strategies for the explicit task-cuing procedure
}

\author{
GORDON D. LOGAN \\ Vanderbilt University, Nashville, Tennessee \\ and \\ CLAUS BUNDESEN \\ University of Copenhagen, Copenhagen, Denmark
}

\begin{abstract}
In two experiments, subjects were given arbitrary letter cues or meaningful word cues that specified the task to be performed on a subsequent target stimulus. Letter and word cues were presented in separate blocks. There were two cues of each type for each task. Three kinds of transitions separated tasks: cue repetitions, in which both the cue and the task repeated; task repetitions, in which the cue changed but the task repeated; and task alternations, in which both the cue and the task changed. Responses were faster for cue than for task repetitions for both cue types. With word cues, task repetitions were not reliably faster than task alternations. With letter cues, task repetitions were reliably faster than task alternations in the first block but not in the second block. The results suggest that subjects responded to the compound of the cue and the target rather than switching task set between trials.
\end{abstract}

The explicit task-cuing procedure is a popular method for studying task switching and executive control (Meiran, 1996; Monsell, 2003; Sudevan \& Taylor, 1987). Subjects are first given a cue that indicates which task to perform, followed by a target stimulus on which to perform the cued task. Cues are presented in random order, and trials are sorted into repetitions and alternations. Reaction time (RT) is generally faster for repetitions than for alternations, and many researchers interpret the difference as reflecting the time required to switch task sets: With repetitions, the current task is the same as the previous one, so there is no need to switch task sets. With alternations, the current task is different from the previous one, so the task set must change before the target can be processed. Changing task sets takes time, which is reflected in the RT difference between repetitions and alternations.

Recently, two studies noted that the usual contrast between repetitions and alternations confounds cue repetition with task repetition (Logan \& Bundesen, 2003; Mayr $\&$ Kliegl, 2003). Both the cue and the task repeat on repetition trials, whereas both the cue and the task change on alternation trials. The RT difference between repetitions and alternations could reflect a benefit for cue repetition as well as or instead of a cost for task switching. To distinguish cue repetition effects from task repetition ef-

This research was supported by National Science Foundation Grants BCS 0133202 and BCS 0218507 and by a grant from the Danish Research Council for the Humanities. We are grateful to Julie Delheimer for testing the subjects and analyzing the data and to Kate Arrington for helpful comments on the manuscript. Correspondence concerning this article should be addressed to G. D. Logan, Department of Psychology, Vanderbilt University, Nashville, TN 37203 (e-mail: gordon.logan@vanderbilt.edu). fects, Logan and Bundesen (2003) and Mayr and Kliegl (2003) used two cues for each task. This procedure produces three kinds of transitions between trials: cue repetitions, in which cues and tasks repeat; task repetitions, in which cues change but tasks remain the same; and task alternations, in which cues and tasks both change. The difference between cue repetitions and task repetitions reflects cue encoding benefits. The difference between task repetitions and task alternations reflects task switching.

Both studies found large RT differences between cue repetitions and task repetitions, suggesting cue encoding benefits. They found different results for the contrast between task repetitions and task alternations. Mayr and Kliegl (2003) found a large advantage for task repetitions, suggesting a substantial task switching effect. Logan and Bundesen (2003) found a small advantage for task repetitions that was significant in one experiment but not in another, suggesting little or no task switching effect. Both studies replicated their results, so it seems clear that task repetitions differ from task alternations in some conditions but not in others. The purpose of the present article is to discover the reasons for this striking difference in results.

Mayr and Kliegl's (2003) procedure differed from Logan and Bundesen's (2003) in several respects. Not only were the cues, targets, and tasks different in the two studies, but the statistical contingencies between cues and targets were different as well. Mayr and Kliegl used letter cues and mapped them arbitrarily onto tasks. Their targets were colored forms that required subjects to discriminate color or form. The letters $G$ and $S$ cued the color task, and the letters $B$ and $W$ cued the form task. Logan and Bundesen used word cues and mapped them meaning- 
fully onto tasks. In one experiment, the targets were digits and subjects discriminated magnitude (greater than or less than 5) or parity (odd or even). Magnitude and High-Low cued the magnitude task and Parity and Odd-Even cued the parity task. In another experiment, the targets were "happy faces" that appeared in one of four quadrants and subjects discriminated the left-right or top-bottom locations (Meiran, 1996). Vertical and Left-Right cued leftright discriminations and Horizontal and Above-Below cued top-bottom discriminations. Mayr and Kliegl eliminated two of the potential sequences between cues to allow cue repetitions, task repetitions, and task alternations to occur equally often (one third of the time), whereas Logan and Bundesen combined cues and targets randomly, so that cue repetitions and task repetitions each occurred on one quarter of the trials and task alternations occurred on half of the trials.

Any of these factors - cues, targets, tasks, or contingencies - could be responsible for the difference in the results of the two studies. The present experiments examined the role of the cues. In Experiment 1, subjects performed parity and magnitude judgments of single digits. Tasks were cued by arbitrary letters $(G, S, B$, or $W)$ and meaningful words (Magnitude, High-Low, Parity, or Odd-Even). In Experiment 2, subjects judged the location of a happy face, using letter cues $(G, S, B$, or $W)$ and word cues (Vertical, Left-Right, Horizontal, or Above-Below). Each subject received letter cues and word cues in different blocks. Half of the subjects experienced letter before word cues, and half experienced word before letter cues.

The difference between the results is important because it supports different interpretations. Mayr and Kliegl (2003) assumed that performance depends on two sequential processes: retrieving the required mapping rules and applying them to the target. The difference between cue repetitions and task repetitions reflects a benefit in rule retrieval time, and the difference between task repetitions and task alternations reflects a benefit in rule application time. Logan and Bundesen (2003) assumed that performance depends on a compound stimulus strategy, in which subjects encode the cue, encode the target, and respond to the combination of the two. The difference between cue repetitions and task repetitions reflects a benefit in cue encoding. The negligible difference between task repetitions and task alternations suggests that no other processes were required to explain the data. Mayr and Kliegl's interpretation suggests that the explicit task cuing procedure reveals the executive processing involved in task switching. Logan and Bundesen's interpretation suggests that the explicit task cuing procedure may not reveal executive control, but instead implies that subjects use the same task set on every trial. There is a benefit for cue repetition, but no task switching is required.

We used formal models to address these interpretations. Two of the models were taken from Logan and Bundesen (2003), and the third was a plausible interpretation of Mayr and Kliegl's (2003) position. All three mod- els account for the time-course function-the reduction in RT as stimulus onset asynchrony (SOA) increasesand for the reduction in the difference between repetitions and alternations as SOA increases. ${ }^{1}$ The simplest model is Logan and Bundesen's Model 2, which implements the compound stimulus strategy: There is a benefit for cue repetition and nothing else. It predicts faster RT for cue repetitions (because the cue stays the same) than for task repetitions and alternations (because the cue changes) and equal RT for task repetitions and alternations. For cue repetitions,

$$
\mathrm{RT}=\mathrm{RT}_{\text {Base }}+\mu_{\mathrm{r}} \exp \left(-\mathrm{SOA} / \mu_{\mathrm{r}}\right),
$$

where $\mu_{\mathrm{r}}$ is the mean time required for cue encoding and $\mathrm{RT}_{\text {Base }}$ is the mean time required to encode and respond to the target. For task repetitions and task alternations,

$$
\mathrm{RT}=\mathrm{RT}_{\text {Base }}+\mu_{\mathrm{a}} \exp \left(-\mathrm{SOA} / \mu_{\mathrm{a}}\right),
$$

where $\mu_{\mathrm{a}}$ is the time required for cue encoding when the cue alternates and $\mathrm{RT}_{\text {Base }}$ is the time required to encode and respond to the target. Cue encoding is faster on cue repetition trials than on task repetition or alternation trials, so $\mu_{\mathrm{r}}<\mu_{\mathrm{a}}$. Target encoding and responding do not differ between trial types (there is no residual switch cost), so $\mathrm{RT}_{\text {Base }}$ is the same in Equations 1 and 2. Logan and Bundesen found that this model fit their data well.

Logan and Bundesen's (2003) Model 2+1 assumes that there is a benefit for cue repetitions, so cue repetitions are faster than task repetitions and task alternations, but that task alternations also require task switching. Both cue encoding and task switching can occur during the SOA. For cue repetitions,

$$
\mathrm{RT}=\mathrm{RT}_{\text {Base }}+\mu_{\mathrm{r}} \exp \left(-\mathrm{SOA} / \mu_{\mathrm{r}}\right),
$$

where $\mu_{\mathrm{r}}$ is the mean cue encoding time and $\mathrm{RT}_{\text {Base }}$ is the time required to encode and respond to the target. For task repetitions,

$$
\mathrm{RT}=\mathrm{RT}_{\text {Base }}+\mu_{\mathrm{a}} \exp \left(-\mathrm{SOA} / \mu_{\mathrm{a}}\right),
$$

where $\mu_{\mathrm{a}}$ is the mean cue encoding time and $\mathrm{RT}_{\text {Base }}$ is the same as in Equation 3. For task alternations, subjects must encode a new cue and switch tasks. Thus

$$
\begin{aligned}
\mathrm{RT}= & \mathrm{RT}_{\mathrm{Base}}+\exp \left(-\mathrm{SOA} / \mu_{\mathrm{a}}\right) \cdot\left(\mu_{\mathrm{a}}+\mu_{\mathrm{s}}\right) \\
& +\frac{1 / \mu_{\mathrm{a}}}{1 / \mu_{\mathrm{a}}-1 / \mu_{\mathrm{s}}}\left[\exp \left(-\mathrm{SOA} / \mu_{\mathrm{s}}\right)\right. \\
& \left.-\exp \left(-\mathrm{SOA} / \mu_{\mathrm{a}}\right)\right] \cdot \mu_{\mathrm{s}}
\end{aligned}
$$

where $\mathrm{RT}_{\text {Base }}$ is the same as in Equations 3 and 4 (there is no residual switch cost), $\mu_{\mathrm{a}}$ is the same as in Equation 4, and $\mu_{\mathrm{s}}$ is the mean task switching time. Logan and Bundesen found that Model 2+1 did not fit the data significantly better than Model 2.

The third model, Model 3, adopts Mayr and Kliegl's (2003) assumption that there is an additional process on task alternation trials that does not occur until the target is 
presented. This is represented as a shift in $\mathrm{RT}_{\mathrm{Base}}$. There is also benefit from cue repetition. Thus, for cue repetitions,

$$
\mathrm{RT}=\mathrm{RT}_{\text {Base-Rep }}+\mu_{\mathrm{r}} \exp \left(-\mathrm{SOA} / \mu_{\mathrm{r}}\right),
$$

where $\mu_{\mathrm{r}}$ is mean rule retrieval time and $\mathrm{RT}_{\text {BaseRep }}$ is the mean time to encode and respond to the target. For task repetitions,

$$
\mathrm{RT}=\mathrm{RT}_{\text {Base-Rep }}+\mu_{\mathrm{a}} \exp \left(-\mathrm{SOA} / \mu_{\mathrm{a}}\right),
$$

where $\mu_{\mathrm{a}}$ is rule retrieval time and $\mathrm{RT}_{\mathrm{BaseRep}}$ is the same as in Equation 6. For task alternations,

$$
\mathrm{RT}=\mathrm{RT}_{\text {Base-Alt }}+\mu_{\mathrm{a}} \exp \left(-\mathrm{SOA} / \mu_{\mathrm{a}}\right),
$$

where $\mu_{\mathrm{a}}$ is the same as in Equation 7 and $\mathrm{RT}_{\text {BaseAlt }}$ is the mean time to apply the mapping rules, encode the target, and respond to it. Model 3 assumes $\mu_{\mathrm{r}}<\mu_{\mathrm{a}}$ and $\mathrm{RT}_{\text {BaseRep }}<$ $\mathrm{RT}_{\text {BaseAlt }}$.

We fit Models 2, 2+1, and 3 to the data from both experiments. Model 2 is nested in Model $2+1$, because Model $2+1$ reduces to Model 2 if task switching time $\left(\mu_{\mathrm{s}}\right)$ vanishes. Model 2 is also nested in Model 3, because Model 3 reduces to Model 2 if $\mathrm{RT}_{\text {BaseRep }}$ equals $\mathrm{RT}_{\text {BaseAlt }}$. We tested the significance of the difference in goodness of fit between Models 2 and $2+1$ and between Models 2 and 3. Better fits for Model $2+1$ than for Model 2 would suggest that task alternations require an additional task switching process that occurs during the SOA. Better fits for Model 3 than for Model 2 would suggest that task alternations require an additional process that does not begin until the target is presented. If neither model fits better than Model 2, there would be no need to postulate different processes for task alternations.

\section{EXPERIMENT 1}

The first experiment had subjects perform parity and magnitude judgments on digits with word and letter cues.

\section{Method}

Subjects. The subjects were 32 individuals from the university community who received payment or course credit for serving in one 1-h session.

Apparatus and Stimuli. The stimuli were displayed on Sony Trinitron monitors controlled by Dell Dimension computers. Subjects responded by pressing the " 4 " or the " 6 " key on the numeric keypad with the index or middle finger of the right hand. The cues were the letters G, S, B, and W and the words Magnitude, High-Low, Parity, and Odd-Even. The targets were the digits 1, 2, 3, 4, 6, 7, 8, and 9 . Each letter and digit was $7 \mathrm{~mm}$ high $\times 4 \mathrm{~mm}$ wide. The word cues were $7 \mathrm{~mm}$ high $\times 28$ (Parity), 37 (Odd-Even and High-Low), or 43 (Magnitude) $\mathrm{mm}$ wide. Viewing distance was not controlled but was approximately $60 \mathrm{~cm}$. At this distance, $1 \mathrm{~cm}$ is approximately $1^{\circ}$ of visual angle.

There were four different kinds of display: (1) a fixation display that contained two plus signs, one above the position the cue would occupy and one below the position the target would occupy; (2) a cue display that contained the cue; (3) a target display that contained the cue and the target (the cue appeared above the target); and (4) a blank display that followed the target display. The fixation display was exposed for $500 \mathrm{msec}$, whereupon it was replaced with the cue display. There were four SOAs between the cue and target displays: $0,300,600$, and $900 \mathrm{msec}$. The target display was exposed until the subject responded, whereupon it was replaced with the blank display for a $500-\mathrm{msec}$ intertrial interval.

Procedure. The basic design of the experiment involved 4 (cues) $\times$ 8 (targets) $\times 4($ SOAs $)=128$ trials. The experiment was divided into two blocks of 384 trials, each including three replications of the basic design. The order of cues, targets, and SOAs was randomized within each set of 128 trials. A separate random order was prepared for each subject. Trials were divided into cue repetitions, task repetitions, and task alternations post hoc. One of the two blocks used arbitrary letter cues: $G$ and $S$ were mapped onto the magnitude task and $B$ and $W$ onto the parity task. The mapping was the same for all subjects, following Mayr and Kliegl (2003). The other block used word cues: Magnitude and High-Low cued the magnitude task, Parity and $O d d-E v e n$ cued the parity task. Half of the subjects had letter cues before word cues, the other half had word cues before letter cues. All subjects pressed the "4" key for High and Odd and the "6" key for Low and Even. Subjects received instructions on the mapping rules but received no practice before beginning the experiment. ${ }^{2}$

\section{Results and Discussion}

Standard analyses. Mean RTs were calculated using correct responses for each subject for cue repetitions, task repetitions, and task alternations for each SOA and separately for letter cues and for word cues in each block. Mean RTs across subjects appear in Figure 1 and Table 1. Percentages of correct responses were calculated for each cell of this design and appear in Table 1. Accuracy was high, and there was no evidence of a speed-accuracy tradeoff, so the analyses focused on RT. The RT and accuracy data were subjected to separate 2 (cue: word vs. letter) $\times 2$ (order: word first vs. letter first) $\times 3$ (transition: cue repetition, task repetition, or task alternation) $\times 4$ (SOA: 0, 300, 600, or $900 \mathrm{msec}$ ) analyses of variance (ANOVAs). The summary tables for the ANOVAs appear in Table 2. Cue repetitions, task repetitions, and task alternations were compared with planned contrasts using the error term for the interaction between cue, transition, and order, using $p<.05$ as the significance level.

The results replicated standard findings in the explicit task-cuing procedure. RT was faster for cue repetitions than for task alternations. RT decreased as SOA increased, and the difference between cue and task repetitions decreased as SOA increased. RT was faster for word than for letter cues, reflecting the greater "transparency" of the word cues, and RT was faster in the second block than in the first, reflecting practice effects.

In the first block, Logan and Bundesen's (2003) results replicated with word cues and Mayr and Kliegl's (2003) results replicated with letter cues. With word cues, RT was $204 \mathrm{msec}$ faster for cue repetitions than for task repetitions $[F(1,60)=50.51]$ but only $8 \mathrm{msec}$ faster for task repetitions than for task alternations $[F(1,60)=0.08]$. With letter cues, RT was $367 \mathrm{msec}$ faster for cue repetitions than for task repetitions $[F(1,60)=164.28]$ and $181 \mathrm{msec}$ faster for task repetitions than for task alternations $[F(1,60)=39.85]$. In the second block, the wordcue data also replicated Logan and Bundesen. RT was $231 \mathrm{msec}$ faster for cue repetitions than for task repeti- 

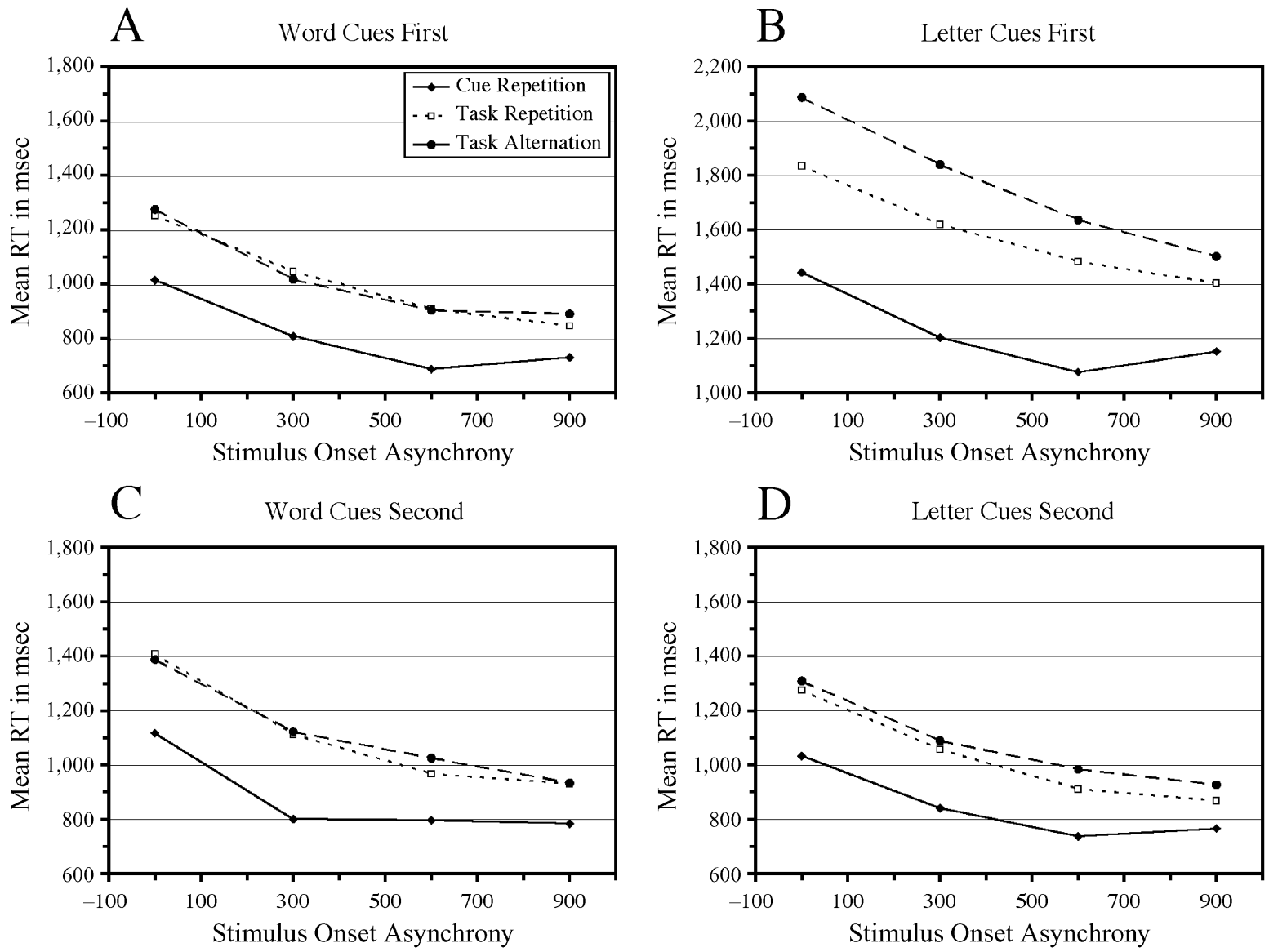

Figure 1. Mean reaction time (RT) as a function of stimulus onset asynchrony for cue repetitions, task repetitions, and task alternations for subjects who received word cues in the first block (A), letter cues in the first block (B), word cues in the second block (C), and letter cues in the second block (D) in the magnitude and parity tasks of Experiment 1.

tions $[F(1,60)=64.80]$ but only $12 \mathrm{msec}$ faster for task repetitions than for task alternations $[F(1,60)=0.18]$. The letter-cue data in the second block resembled Logan and Bundesen's results as much as Mayr and Kliegl's. RT was $184 \mathrm{msec}$ faster for cue repetitions than for task rep- etitions $[F(1,60)=41.29]$ and $50 \mathrm{msec}$ faster for task repetitions than for task alternations $[F(1,60)=2.99$, $p<.10] .^{3}$

Model fitting. Models 2, 2+1, and 3 were fit to the mean RTs in Table 1 using the Solver routine in Microsoft

Table 1

Mean Reaction Time (RT, in Milliseconds) and Percentage of Correct Responses (PC) as a Function of Stimulus Onset Asynchrony (SOA) and Transition (Cue Repetition, Task Repetition, and Task Alternation) for Word and Letter Cues That Occurred in the First and Second Blocks in Experiment 1

\begin{tabular}{|c|c|c|c|c|c|c|c|c|c|c|c|c|}
\hline \multirow[b]{2}{*}{ SOA } & \multicolumn{2}{|c|}{$\mathrm{CR}$} & \multicolumn{2}{|c|}{$\mathrm{TR}$} & \multicolumn{2}{|c|}{$\mathrm{TA}$} & \multicolumn{2}{|c|}{$\mathrm{CR}$} & \multicolumn{2}{|c|}{ TR } & \multicolumn{2}{|c|}{ TA } \\
\hline & RT & $\mathrm{PC}$ & RT & $\mathrm{PC}$ & RT & $\mathrm{PC}$ & RT & $\mathrm{PC}$ & RT & $\mathrm{PC}$ & RT & $\mathrm{PC}$ \\
\hline & \multicolumn{6}{|c|}{ Word First } & \multicolumn{6}{|c|}{ Letter First } \\
\hline 0 & 1,015 & 97 & 1,252 & 96 & 1,275 & 93 & 1,443 & 96 & 1,835 & 93 & 2,087 & 91 \\
\hline 300 & 807 & 98 & 1,046 & 96 & 1,017 & 93 & 1,202 & 96 & 1,620 & 92 & 1,840 & 92 \\
\hline 600 & 686 & 95 & 908 & 95 & 903 & 94 & 1,076 & 95 & 1,483 & 95 & 1,636 & 93 \\
\hline \multirow[t]{2}{*}{900} & 730 & 96 & 846 & 95 & 890 & 95 & 1,152 & 98 & 1,403 & 94 & 1,501 & 93 \\
\hline & \multicolumn{6}{|c|}{ Word Second } & \multicolumn{6}{|c|}{ Letter Second } \\
\hline 0 & 1,117 & 98 & 1,408 & 98 & 1,388 & 95 & 1,032 & 97 & 1,275 & 95 & 1,309 & 94 \\
\hline 300 & 801 & 97 & 1,113 & 96 & 1,122 & 95 & 840 & 97 & 1,057 & 95 & 1,089 & 93 \\
\hline 600 & 795 & 97 & 967 & 98 & 1,025 & 96 & 737 & 96 & 911 & 95 & 934 & 95 \\
\hline 900 & 784 & 97 & 931 & 98 & 933 & 97 & 766 & 96 & 868 & 95 & 927 & 96 \\
\hline
\end{tabular}

Note-CR, cue repetition; TR, task repetition; TA, task alternation. 
Table 2

Summary Tables for Analyses of Variance Performed on the Mean Reaction Times and the Percentage of Correct Responses in Experiment 1

\begin{tabular}{lcrrrrr}
\hline & & \multicolumn{2}{c}{ Reaction Time } & & \multicolumn{2}{c}{ Accuracy } \\
\cline { 7 - 7 } \cline { 6 - 7 } \multicolumn{1}{c}{ Effect } & $d f$ & \multicolumn{1}{c}{$F$} & \multicolumn{1}{c}{$M S_{\mathrm{e}}$} & & $F$ & $M S_{\mathrm{e}}$ \\
\hline Cue (C) & 1,30 & $67.86^{*}$ & $195,894.24$ & & $17.68^{*}$ & 38.60 \\
Transition (T) & 2,60 & $121.58^{*}$ & $56,078.75$ & & $15.97^{*}$ & 27.71 \\
SOA (S) & 3,90 & $272.49^{*}$ & $22,312.91$ & & 1.49 & 18.36 \\
Order (O) & 1,30 & $29.82^{*}$ & $627,306.90$ & & 0.25 & 196.25 \\
$\mathrm{C} \times \mathrm{O}$ & 1,30 & $50.97^{*}$ & $195,894.24$ & & $5.95 \dagger$ & 38.60 \\
$\mathrm{~T} \times \mathrm{O}$ & 2,60 & $8.64^{*}$ & $56,078.75$ & & 0.01 & 27.71 \\
$\mathrm{~S} \times \mathrm{O}$ & 3,90 & 2.03 & $22,312.91$ & & 1.67 & 18.36 \\
$\mathrm{C} \times \mathrm{T}$ & 2,60 & $16.72^{*}$ & $26,236.53$ & & 1.94 & 23.65 \\
$\mathrm{C} \times \mathrm{S}$ & 3,90 & 0.87 & $18,851.68$ & & 2.36 & 14.78 \\
$\mathrm{~T} \times \mathrm{S}$ & 6,180 & $8.11^{*}$ & $12,851.75$ & & 2.10 & 18.78 \\
$\mathrm{C} \times \mathrm{T} \times \mathrm{O}$ & 2,60 & $12.24^{*}$ & $26,236.53$ & & 1.22 & 23.65 \\
$\mathrm{C} \times \mathrm{S} \times \mathrm{O}$ & 3,90 & 0.75 & $18,851.68$ & & 0.87 & 14.78 \\
$\mathrm{~T} \times \mathrm{S} \times \mathrm{O}$ & 6,180 & 1.52 & $12,851.75$ & & 0.54 & 18.78 \\
$\mathrm{C} \times \mathrm{S} \times \mathrm{T}$ & 6,180 & 0.77 & $14,007.93$ & & 0.34 & 13.36 \\
$\mathrm{C} \times \mathrm{T} \times \mathrm{S} \times \mathrm{O}$ & 6,180 & 1.08 & $14,007.93$ & & 0.49 & 13.36 \\
\hline$* p<.01$. & $\dagger p<.05$. & & & & &
\end{tabular}

${ }^{*} p<.01 . \quad{ }^{\dagger} p<.05$.

Excel to minimize root-mean squared deviations (RMSD) between predicted and observed values. The values of the best-fitting parameters and measures of goodness of fit (RMSD and $r$, the correlation between observed and predicted values) are presented in Table 3 . To assess Model 2, Equation 1 was fit to the mean RTs for cue repetitions and Equation 2 to the mean RTs for task repetitions and task alternations. All three conditions were fit simultaneously within each cue type and block. There were three parameters: cue encoding time $\mu_{\mathrm{r}}$ for cue repetitions, cue encoding time $\mu_{\mathrm{a}}$ for task repetitions and alternations, and a common value of $\mathrm{RT}_{\mathrm{Base}}$ for all three conditions. ${ }^{4}$
To assess Model 2+1, Equation 3 was fit to the mean RTs for cue repetitions, Equation 4 to the mean RTs for task repetitions, and Equation 5 to the mean RTs for task alternations. All three conditions were fit simultaneously within each cue type and block. There were four parameters: cue encoding time $\mu_{\mathrm{r}}$ for cue repetitions, cue encoding time $\mu_{\mathrm{a}}$ for task repetitions and task alternations, task switching time $\mu_{\mathrm{s}}$ for task alternations, and a common value of $\mathrm{RT}_{\text {Base }}$ for all three conditions. Model $2+1$ did not fit the data better than Model 2 for either of the word-cue conditions $[F(1,8)=0.00$ and 0.01 for the word cue first and word cue second conditions, respectively]. Model 2+1 fit better than Model 2 for letter cues first $[F(1,8)=34.23]$ but not for letter cues second $[F(1,8)=1.57]$.

To assess Model 3, Equation 6 was fit to the mean RTs for cue repetitions, Equation 7 to the mean RTs for task repetitions, and Equation 8 to the mean RTs for task alternations. All three conditions were fit simultaneously within each cue type and block. There were four parameters: cue encoding time $\mu_{\mathrm{r}}$ for cue repetitions, cue encoding time $\mu_{\mathrm{a}}$ for task repetitions and alternations, a common value of $\mathrm{RT}_{\text {BaseRep }}$ for cue repetitions and task repetitions, and a unique value of $\mathrm{RT}_{\text {BaseAlt }}$ for task alternations. Model 3 did not fit the word-cue data significantly better than Model $2[F(1,8)=0.48$ and 0.34 for word cues first and word cues second, respectively]. Model 3 fit the letter-cue data better than did Model 2 $[F(1,8)=35.89$ and 12.38 for letter cues first and letter cues second, respectively].

\section{EXPERIMENT 2}

The second experiment replicated the first, except that subjects now judged the location of a happy face.

Table 3

Parameter Values and Measures of Goodness of Fit for Models Fitted to the Data From Experiment 1

\begin{tabular}{|c|c|c|c|c|c|c|c|c|}
\hline & $\mu_{\mathrm{r}}$ & $\mu_{\mathrm{a}}$ & $\mu_{\mathrm{s}}$ & $\mathrm{RT}_{\text {BaseRep }}$ & $\mathrm{RT}_{\text {Base }}$ & $\mathrm{RT}_{\text {BaseAlt }}$ & $r$ & RMSD \\
\hline \multicolumn{9}{|c|}{ Model 2} \\
\hline Word first & 277 & 559 & & & 715 & & .987 & 29 \\
\hline Word second & 304 & 625 & & & 759 & & .986 & 33 \\
\hline Letter first & 307 & 885 & & & 1,102 & & .958 & 83 \\
\hline Letter second & 257 & 548 & & & 759 & & .986 & 30 \\
\hline \multicolumn{9}{|c|}{ Model $2+1$} \\
\hline Word first & 277 & 559 & 1 & & 716 & & .987 & 29 \\
\hline Word second & 304 & 623 & 6 & & 759 & & .986 & 33 \\
\hline Letter first & 292 & 768 & 243 & & 1,114 & & .992 & 37 \\
\hline Letter second & 253 & 529 & 45 & & 762 & & .988 & 27 \\
\hline \multicolumn{9}{|c|}{ Model 3} \\
\hline Word first & 279 & 551 & & 714 & & 730 & .988 & 28 \\
\hline Word second & 307 & 618 & & 757 & & 773 & .987 & 33 \\
\hline Letter first & 318 & 791 & & 1,094 & & 1,277 & .992 & 35 \\
\hline Letter second & 266 & 522 & & 753 & & 808 & .994 & 19 \\
\hline
\end{tabular}

Note $-\mu_{\mathrm{r}}$, mean cue encoding time on repetition trials; $\mu_{\mathrm{a}}$, mean cue encoding time on alternation trials; $\mu_{\mathrm{s}}$, mean set switching time; $\mathrm{RT}_{\mathrm{Base}}$, base reaction time; $\mathrm{RT}_{\text {BaseRep }}$, base reaction time when mapping repeats; $\mathrm{RT}_{\mathrm{BaseAlt}}$, base reaction time when mapping alternates; $r$, correlation between observed and predicted values; RMSD, root-mean squared deviation between observed and predicted values. 


\section{Method}

Subjects. The subjects were 32 individuals from the university community who received course credit or payment for serving in one 1-h session.

Apparatus and Stimuli. Experiment 2 used the same apparatus as did Experiment 1. Subjects responded on the " 1 " and " 9 " or the " 7 " and " 3 " keys on the numeric keypad using the index fingers of each hand. The fixation display was a $4 \times 4$ grid that was $32 \mathrm{~mm}$ high $\times 38 \mathrm{~mm}$ wide. After $500 \mathrm{msec}$, the cue appeared $6 \mathrm{~mm}$ above the grid. All cues were $5 \mathrm{~mm}$ high. Vertical was $24 \mathrm{~mm}$ wide, LeftRight and Horizontal were $31 \mathrm{~mm}$ wide, and Above-Below was $34 \mathrm{~mm}$ wide. Letter cues were $3 \mathrm{~mm}$ wide. After an SOA of 0, 300, 600 , or $900 \mathrm{msec}$, a happy-face target appeared in the center of one of the four quadrants. It was $5 \mathrm{~mm}$ high and $3 \mathrm{~mm}$ wide. The cue and target were exposed until the subject responded, whereupon the display went blank for a 500-msec intertrial interval.

Procedure. The procedure was the same as in Experiment 1. The basic design involved 4 (cues) $\times 4$ (targets) $\times 4$ (SOAs) $=64$ trials. Each subject experienced two blocks of 384 trials, one with letter cues and one with word cues. For all subjects, $G$ and $S$ cued the left-right task and $B$ and $W$ cued the above-below task. Half of the subjects had letter cues before word cues, the other half had the word cues first. For their responses, half of the subjects pressed " 1 " for Left and Below and "9" for Right and Above, the other half pressed
"3" for Right and Below and "7" for Left and Above. Subjects were given instructions about the mapping rules but received no practice. ${ }^{5}$

\section{Results}

Standard analyses. Mean RTs were calculated for correct responses for each subject in each condition, separating the first block from the second. Mean RTs across subjects appear in Figure 2 and Table 4. Percentages of correct responses in each cell appear in Table 4. RT and accuracy data were subjected to 2 (cue: word vs. letter) $\times$ 2 (order: word first vs. letter first) $\times 3$ (transition: cue repetition, task repetition, or task alternation) $\times 4$ (SOA: $0,300,600$, or $900 \mathrm{msec}$ ) ANOVAs. The summary tables appear in Table 5. Differences between cue repetitions, task repetitions, and task alternations were assessed with planned contrasts using the error term from the interaction between cue, transition, and order and $p<.05$ as the significance level.

RT was faster for cue repetitions than for task alternations. RT decreased as SOA increased, and the difference between cue repetitions and task repetitions decreased as
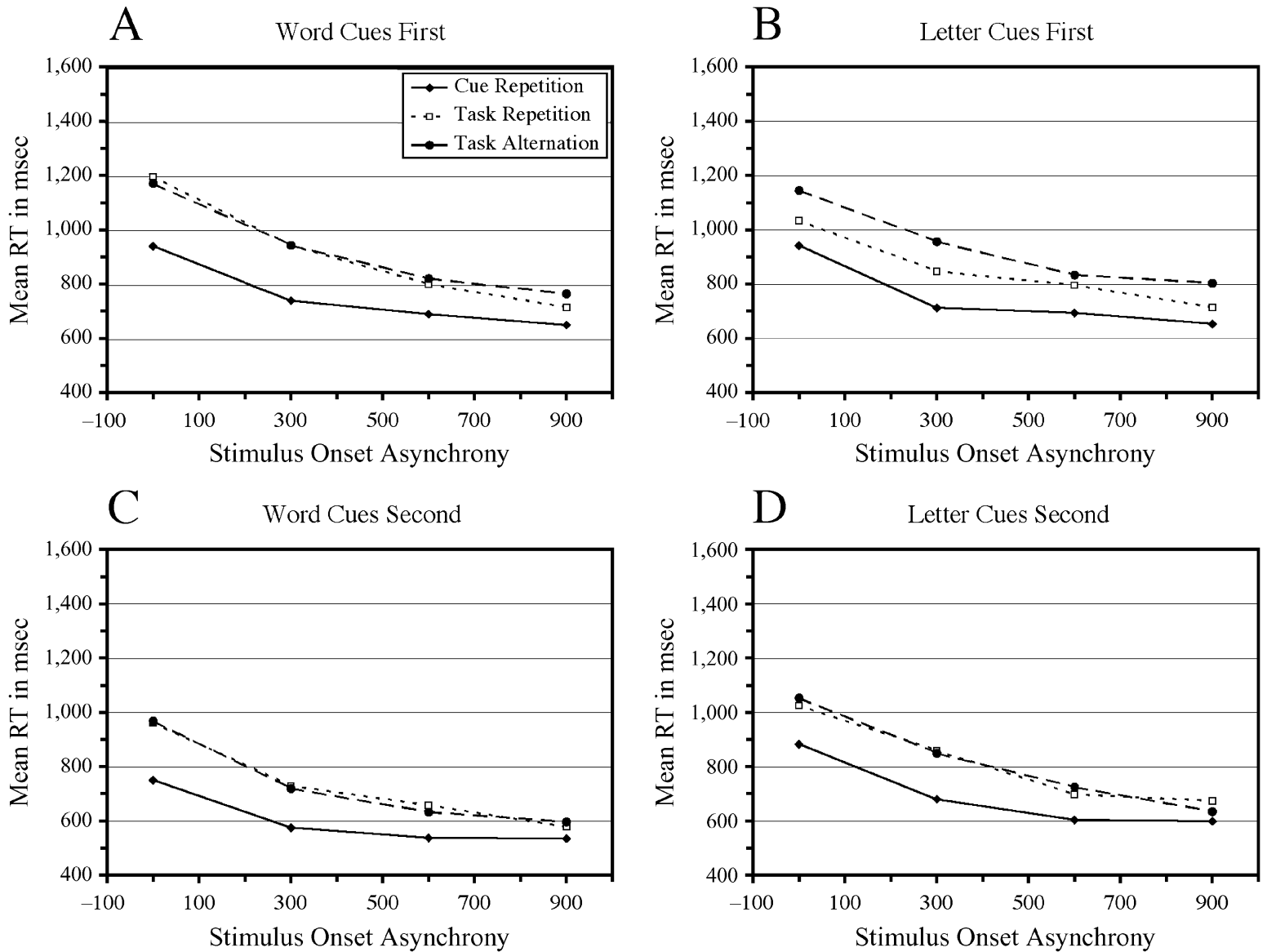

Figure 2. Mean reaction time (RT) as a function of stimulus onset asynchrony for cue repetitions, task repetitions, and task alternations for subjects who received word cues in the first block $(A)$, letter cues in the first block (B), word cues in the second block (C), and letter cues in the second block (D) in the above-below and left-right tasks of Experiment 2. 
Table 4

Mean Reaction Time (RT, in Milliseconds) and Percentage of Correct Responses (PC) as a Function of Stimulus Onset Asynchrony (SOA) and Transition (Cue Repetition, Task Repetition, and Task Alternation) for Word and Letter Cues That Occurred in the First and Second Blocks in Experiment 2

\begin{tabular}{|c|c|c|c|c|c|c|c|c|c|c|c|c|}
\hline \multirow[b]{2}{*}{ SOA } & \multicolumn{2}{|c|}{$\mathrm{CR}$} & \multicolumn{2}{|c|}{ TR } & \multicolumn{2}{|c|}{ TA } & \multicolumn{2}{|c|}{$\mathrm{CR}$} & \multicolumn{2}{|c|}{ TR } & \multicolumn{2}{|c|}{ TA } \\
\hline & RT & $\mathrm{PC}$ & RT & $\mathrm{PC}$ & RT & $\mathrm{PC}$ & RT & $\mathrm{PC}$ & RT & $\mathrm{PC}$ & RT & $\overline{\mathrm{PC}}$ \\
\hline & \multicolumn{6}{|c|}{ Word First } & \multicolumn{6}{|c|}{ Letter First } \\
\hline 0 & 939 & 97 & 1,196 & 95 & 1,171 & 93 & 942 & 94 & 1,033 & 90 & 1,145 & 88 \\
\hline 300 & 739 & 98 & 942 & 97 & 943 & 95 & 712 & 94 & 847 & 92 & 956 & 91 \\
\hline 600 & 689 & 98 & 799 & 96 & 820 & 96 & 693 & 93 & 795 & 93 & 833 & 92 \\
\hline \multirow[t]{2}{*}{900} & 649 & 98 & 714 & 98 & 764 & 96 & 653 & 95 & 713 & 93 & 803 & 93 \\
\hline & \multicolumn{6}{|c|}{ Word Second } & \multicolumn{6}{|c|}{ Letter Second } \\
\hline 0 & 749 & 97 & 961 & 94 & 968 & 92 & 882 & 96 & 1,025 & 93 & 1,053 & 92 \\
\hline 300 & 574 & 96 & 729 & 97 & 719 & 95 & 680 & 96 & 859 & 95 & 849 & 95 \\
\hline 600 & 537 & 95 & 657 & 95 & 632 & 94 & 602 & 96 & 697 & 95 & 724 & 94 \\
\hline 900 & 535 & 95 & 577 & 96 & 596 & 96 & 599 & 95 & 674 & 95 & 634 & 94 \\
\hline
\end{tabular}

Note-CR, cue repetition; TR, task repetition; TA, task alternation.

SOA increased. RT was faster for word than for letter cues, and RT was faster in the second block than in the first.

In the first block, Logan and Bundesen's (2003) results replicated with word cues. Cue repetitions were $159 \mathrm{msec}$ faster than task repetitions $[F(1,60)=80.78]$, and task repetitions were only $12 \mathrm{msec}$ faster than task alternations $[F(1,60)=0.44]$. Mayr and Kliegl's (2003) results replicated with letter cues. Cue repetitions were $97 \mathrm{msec}$ faster than task repetitions $[F(1,60)=30.16]$, and task repetitions were $87 \mathrm{msec}$ faster than task alternations $[F(1,60)=24.40]$. In the second block, Logan and Bundesen's results replicated with word and letter cues. Cue repetitions were 132 and $123 \mathrm{msec}$ faster than task repetitions for word and letter cues, respectively $[F(1,60)=56.06$ and 48.49 , respectively]. Task repetitions were $2 \mathrm{msec}$ slower than task alternations with word cues and $1 \mathrm{msec}$ faster with letter cues $[F(1,60)=$ 0.02 and 0.01 , respectively]. ${ }^{6}$

Table 5

Summary Tables for Analyses of Variance Performed on the Mean Reaction Times and the Percentage of Correct Responses in Experiment 2

\begin{tabular}{lcccccr}
\hline & & \multicolumn{2}{c}{ Reaction Time } & & \multicolumn{2}{c}{ Accuracy } \\
\cline { 3 - 4 } \cline { 6 - 7 } \multicolumn{1}{c}{ Effect } & $d f$ & \multicolumn{1}{c}{$F$} & \multicolumn{1}{c}{$M S_{\mathrm{e}}$} & & $F$ & $M S_{\mathrm{e}}$ \\
\hline Cue (C) & 1,30 & 2.59 & $83,614.44$ & & $9.67^{*}$ & 85.55 \\
Transition (T) & 2,60 & $97.07^{*}$ & $17,623.86$ & & $15.14^{*}$ & 25.22 \\
SOA (S) & 3,90 & $408.07^{*}$ & $11,054.34$ & & $5.78^{*}$ & 18.00 \\
Order (O) & 1,30 & 1.06 & $517,361.10$ & & 3.64 & 245.87 \\
$\mathrm{C} \times \mathrm{O}$ & 1,30 & $35.39^{*}$ & $83,614.44$ & & 2.12 & 85.55 \\
$\mathrm{~T} \times \mathrm{O}$ & 2,60 & 1.26 & $17,623.86$ & & 0.53 & 25.22 \\
$\mathrm{~S} \times \mathrm{O}$ & 3,90 & $3.69 \dagger$ & $11,054.34$ & & 0.95 & 18.00 \\
$\mathrm{C} \times \mathrm{T}$ & 2,60 & 3.10 & $9,983.09$ & & 0.49 & 25.59 \\
$\mathrm{C} \times \mathrm{S}$ & 3,90 & 1.22 & $5,738.35$ & & 1.01 & 16.04 \\
$\mathrm{~T} \times \mathrm{S}$ & 6,180 & $9.69^{*}$ & $6,681.29$ & & $2.33 \dagger$ & 16.88 \\
$\mathrm{C} \times \mathrm{T} \times \mathrm{O}$ & 2,60 & $5.29^{*}$ & $9,983.09$ & & 0.99 & 25.59 \\
$\mathrm{C} \times \mathrm{S} \times \mathrm{O}$ & 3,90 & 0.53 & $5,738.25$ & & 1.87 & 16.04 \\
$\mathrm{~T} \times \mathrm{S} \times \mathrm{O}$ & 6,180 & 0.91 & $6,681.29$ & & 0.92 & 16.88 \\
$\mathrm{C} \times \mathrm{S} \times \mathrm{T}$ & 6,180 & 2.19 & $6,879.00$ & & 0.42 & 20.73 \\
$\mathrm{C} \times \mathrm{T} \times \mathrm{S} \times \mathrm{O}$ & 6,180 & 0.64 & $6,879.00$ & & 0.29 & 20.73 \\
\hline$* p<.01$. & $\dagger<.05$. & & & &
\end{tabular}

Model fits. Models 2, 2+1, and 3 were fit to the data in Table 4 using the same procedure as was used in Experiment 1 . The best-fitting parameters and measures of goodness of fit appear in Table 6 . With word cues, Model $2+1$ did not fit better than Model 2 in either block $[F(1,8)=$ 0.00 and 0.00 ]. With letter cues, Model $2+1$ fit better than Model 2 in the first block $[F(1,8)=7.07]$ but not in the second block $[F(1,8)=0.14]$.

With word cues, Model 3 did not fit better than Model 2 in either block $[F(1,8)=1.00$ and 0.00 for the first and second blocks, respectively]. With letter cues, Model 3 fit better than Model 2 in the first block $[F(1,8)=29.91]$ but not in the second block $[F(1,8)=0.03]$.

\section{GENERAL DISCUSSION}

In both experiments, RT decreased as SOA increased, reproducing the standard time-course function. RT was faster for cue repetitions than for task alternations, and the difference decreased as SOA increased. These effects confound cue repetition with task repetition. The key results were the differences between task repetitions and task alternations. Both transitions involve cue changes, but only task alternations involve task changes. There was no reliable difference between task repetitions and task alternations with word cues in either block, or with letter cues in the second block in either experiment. Reliable differences were found only with letter cues in the first block. This finding suggests that the difference in results between Logan and Bundesen's (2003) study and Mayr and Kliegl's (2003) study was due to the cues they used.

The model fits showed substantial cue repetition benefits in each condition of each experiment. No other parameters were required to account for the word-cue data. With letter cues, an extra task switching parameter (Model 2+1) was required for task alternation trials in the first block of both experiments. An extra rule application parameter (Model 3) was required for task alternation trials in both blocks of Experiment 1 and in the first block of Experi- 
Table 6

Parameter Values and Measures of Goodness of Fit for Models Fitted to the Data from Experiment 2

\begin{tabular}{|c|c|c|c|c|c|c|c|c|}
\hline & $\mu_{\mathrm{r}}$ & $\mu_{\mathrm{a}}$ & $\mu_{\mathrm{s}}$ & $\mathrm{RT}_{\text {BaseRep }}$ & $\mathrm{RT}_{\text {Base }}$ & $\mathrm{RT}_{\text {BaseAlt }}$ & $r$ & RMSD \\
\hline \multicolumn{9}{|c|}{ Model 2} \\
\hline Word first & 301 & 541 & & & 636 & & .997 & 13 \\
\hline Word second & 212 & 426 & & & 531 & & .997 & 12 \\
\hline Letter first & 233 & 433 & & & 682 & & .952 & 44 \\
\hline Letter second & 294 & 477 & & & 579 & & .994 & 17 \\
\hline \multicolumn{9}{|c|}{ Model 2+1 } \\
\hline Word first & 301 & 540 & 1 & & 636 & & .997 & 13 \\
\hline Word second & 212 & 425 & 1 & & 531 & & .997 & 12 \\
\hline Letter first & 224 & 372 & 127 & & 689 & & .975 & 33 \\
\hline Letter second & 293 & 473 & 8 & & 580 & & .994 & 17 \\
\hline \multicolumn{9}{|c|}{ Model 3} \\
\hline Word first & 304 & 537 & & 634 & & 645 & .997 & 13 \\
\hline Word second & 212 & 426 & & 531 & & 531 & .997 & 12 \\
\hline Letter first & 254 & 393 & & 665 & & 759 & .990 & 20 \\
\hline Letter second & 295 & 476 & & 579 & & 581 & .994 & 17 \\
\hline
\end{tabular}

Note $-\mu_{\mathrm{r}}$, mean cue encoding time on repetition trials; $\mu_{\mathrm{a}}$, mean cue encoding time on alternation trials; $\mu_{\mathrm{s}}$, mean set switching time; $\mathrm{RT}_{\mathrm{Base}}$, base reaction time; $\mathrm{RT}_{\mathrm{BaseRep}}$, base reaction time when mapping repeats; $\mathrm{RT}_{\mathrm{BaseAl}}$, base reaction time when mapping alternates; $r$, correlation between observed and predicted values; RMSD, root-mean squared deviation between observed and predicted values.

ment 2. Model 2+1 fit the data as well as Model 3, so it remains unclear whether the extra process went on during the SOA or began when the target appeared.

The model fits can be explained in terms of the compound stimulus strategy: Subjects encode the cue, encode the target, and respond to the compound. ${ }^{7}$ Cue encoding benefits from cue repetition, but the same task set is used for all trials. This strategy accounts for the word-cue data, because it predicts no difference between task repetitions and task alternations. It can be extended to the letter-cue data by assuming that task names mediate retrieval of the correct response, at least early in practice: Subjects encode the letter, retrieve the task name associated with it, and use the task name and the target as a joint retrieval cue that pulls the appropriate response from memory. Retrieval of the mediator could be facilitated by task repetition-which entails mediator repetition-so task repetition trials would be faster than task alternation trials, as we found with letter cues. The compound stimulus strategy can be implemented easily in Bundesen's (1990) theory of visual attention or in recent extensions of it (Logan \& Gordon, 2001).

Consider Mayr and Kliegl's (2003) perspective: The results with letter cues in the first block replicate their findings, so their original explanation applies - the difference between cue repetition and task repetition reflects a benefit in retrieving mapping rules, and the difference between task repetition and task alternation reflects a benefit in applying the mapping rules to the target. However, it is not clear why the difference between task repetitions and task alternations should disappear with word cues or with letter cues in the second block.

Word cues reduce the difference between task repetitions and task alternations, but they do not always elim- inate it entirely (Logan \& Bundesen, 2003). On the one hand, the small residual difference may reflect a fast task switching process that occurs on every trial or a slow task switching process that occurs on a small proportion of trials. On the other hand, it could reflect facilitation of memory retrieval in the compound stimulus strategy. Cues that refer to the same task may prime each other or facilitate retrieval of the same mediator.

What is at stake theoretically is the interpretation of the explicit task cuing procedure as a method for investigating executive control. If the compound stimulus strategy provides the best description of performance, the explicit task cuing procedure is not a viable method for investigating executive control. It may be possible, though, to find task switching with other tasks that do not support the compound stimulus strategy: Some tasks may be too complex to be performed by memory retrieval. Other tasks may require switching attention between stimulus dimensions or between stimuli before memory retrieval can be engaged. The limits of the compound stimulus strategy remain to be discovered. The present results suggest that the elusive homunculus is very clever, and we must be even more clever to capture it in our experiments.

\section{REFERENCES}

Bundesen, C. (1990). A theory of visual attention. Psychological Review, 97, 523-547.

LoGAN, G. D., \& BUNDESEN, C. (2003). Clever homunculus: Is there an endogenous act of control in the explicit task-cuing procedure? Journal of Experimental Psychology: Human Perception \& Performance, 29, 575-599.

LOGAN, G. D., \& GoRDON, R. D. (2001). Executive control of visual attention in dual-task situations. Psychological Review, 108, 393-434. MAYr, U., \& KLIEgL, R. (2003). Differential effects of cue changes and 
task changes on task-set selection costs. Journal of Experimental Psychology: Learning, Memory, \& Cognition, 29, 362-372.

MEIRAN, N. (1996). Reconfiguration of processing mode prior to task performance. Journal of Experimental Psychology: Learning, Memory, \& Cognition, 22, 1423-1442.

Monsell, S. (2003). Task switching. Trends in Cognitive Sciences, 7, 134-140.

SuDEVAN, P., \& TAYLOR, D. A. (1987). The cuing and priming of cognitive operations. Journal of Experimental Psychology: Human Perception \& Performance, 13, 89-103.

\section{NOTES}

1. The models assume that the time-course function reflects the cumulative distribution of finishing times for processes that encode the cue and switch tasks or apply mapping rules. RT is fast if these processes have finished and slow if they have not. As SOA increases, the probability that the processes have finished increases, and RT decreases accordingly. The models assume that the finishing-time distributions are exponential. Logan and Bundesen (2003) provide justifications for these assumptions and more complete explanations of the models.

2 . To assess the effects of practice on the key results, we calculated mean reaction time for the first 128 trials (one replication of the basic design) separately from the last 256 trials (two replications). The data were analyzed in a 2 (cue type) $\times 3$ (transition) $\times 4$ (SOA) $\times 2$ (order) $\times$ 3 (subblock of 128 trials) ANOVA. Fisher's least significant difference (LSD) for $p<.05$, calculated from the interaction between cue type, transition, order, and subblock, was $59.48 \mathrm{msec}$. For word cues in the first block, the difference between task repetitions and cue repetitions was $302 \mathrm{msec}$ in the first 128 trials and $171 \mathrm{msec}$ in the last 256 trials (both significant by the LSD criterion). The difference between task alternations and task repetitions was $32 \mathrm{msec}$ in the first 128 trials and $-25 \mathrm{msec}$ in the last 256 trials (neither was significant by LSD). For word cues in the second block, the differences were $365,169,-85$, and $59 \mathrm{msec}$, respectively (the first three were significant by LSD). For letter cues in the first block, the differences were 525, 330, 356, and $144 \mathrm{msec}$, respectively (all significant by LSD). For letter cues in the second block, the differences were $205,180,90$, and $-6 \mathrm{msec}$, respectively (the first three were significant by LSD). Thus, the pattern observed in the means averaged across block replicated over practice, although the differences were somewhat noisier due to the smaller number of observations going into each difference.

3. These critical effects were evaluated in the accuracy data with planned contrasts using the interaction between transition, cue, and order and $p<.05$ as the significance level. With word cues in the first block, the difference between cue repetitions and task repetitions was not significant $[F(1,60)=1.35]$, but the difference between task repetitions and task alternations was $[F(1,60)=4.14]$. With word cues in the second block, cue repetitions were not different from task repetitions $[F(1,60)=$ $0.08]$, but task repetitions were more accurate than task alternations $[F(1,60)=4.14]$. The differences between task repetitions and alternations were small (less than 2\%) and were not replicated in Experiment 2, so they need not compromise the RT data. Neither difference was significant with letter cues in the first block $[F(1,60)=1.35$ and 2.11 , respectively] or in the second block $[F(1,60)=3.04$ and 0.34 , respectively].

4. Model 2 uses three parameters to fit 12 data points, and Models $2+1$ and 3 use four parameters. The ratio of data points to param- eters is low and may not appear to constrain the fits enough, but Logan and Bundesen (2003) fit Models 2 and $2+1$ to two experiments with 30 data points and the same number of parameters, increasing the ratio substantially. The models provided a good account of the time-course functions in those experiments, so using them here seems reasonable.

5. To assess the effects of practice on the key results, we calculated mean reaction time for the first 128 trials (the first two replications of the basic design) separately from the last 256 trials (the last four replications). The data were analyzed in a 2 (cue type) $\times 3$ (transition) $\times 4$ $(\mathrm{SOA}) \times 2$ (order) $\times 3$ (subblock of 128 trials) ANOVA. Fisher's LSD for $p<.05$, calculated from the interaction between cue type, transition, order, and subblock, was $42.47 \mathrm{msec}$. For word cues in the first block, the difference between task repetitions and cue repetitions was $362 \mathrm{msec}$ in the first 128 trials and $136 \mathrm{msec}$ in the last 256 trials (both significant by LSD). The difference between task alternations and task repetitions was $6 \mathrm{msec}$ in the first 128 trials and $0 \mathrm{msec}$ in the last 256 trials (neither significant by LSD). For word cues in the second block, the differences were $178,123,-26$, and $2 \mathrm{msec}$, respectively (only the first two were significant by LSD). For letter cues in the first block, the differences were 186, 110, 142, and $64 \mathrm{msec}$, respectively (all were significant by LSD). For letter cues in the second block, the differences were $192,99,-41$, and $44 \mathrm{msec}$, respectively (the first two and the last were significant by LSD). The pattern observed in the means averaged across block replicated over practice, although the differences were noisier due to the smaller number of observations.

6 . The critical effects were evaluated in the accuracy data with planned contrasts using the interaction between transition, cue, and order and $p<.05$ as the significance level. With word cues in the first block, the difference between cue repetitions and task repetitions was not significant $[F(1,60)=1.95]$, nor was the difference between task repetitions and task alternations $[F(1,60)=2.81]$. With word cues in the second block, neither difference was significant $[F(1,60)=0.08$ and 1.95 , respectively]. With letter cues in the first block, cue repetitions were more accurate than task repetitions $[F(1,60)=5.00]$, but task repetitions did not differ significantly from task alternations $[F(1,60)=1.25]$. With letter cues in the second block, neither difference was significant $[F(1,60)=$ 1.95 and 0.70 , respectively].

7. The compound stimulus strategy can be interpreted as reflecting associations between relatively uninterpreted cues, targets, and responses (e.g., "squiggle1" and "squiggle2" mean "press key X"). These associations may take some time to be acquired. The strategy can also be interpreted as a compound retrieval cue strategy, in which the cue and the target are interpreted and combined in a joint retrieval cue to pull the required information from semantic memory (e.g., Odd-Even and "7" retrieve "Odd," so the response corresponding to "Odd" is executed). Our subjects likely knew which digits were odd and which were even without having to compute parity, and they likely knew which digits were greater or less than 5 without having to subtract, so it seems reasonable to assume they retrieved the answers from memory. From the perspective of the compound retrieval cue strategy, there is only one task set for all trials: identify the cue, identify the target, use them as a joint retrieval cue, and report what they pull out of memory.

(Manuscript received June 2, 2003; revision accepted for publication November 5, 2003.) 